\title{
Brief communication: Impacts of ocean-wave-induced breakup of Antarctic sea ice via thermodynamics in a stand-alone version of the CICE sea-ice model
}

\author{
Luke G. Bennetts ${ }^{1}$, Siobhan O'Farrell ${ }^{2}$, and Petteri Uotila ${ }^{3}$ \\ ${ }^{1}$ School of Mathematical Sciences, University of Adelaide, Adelaide, SA, Australia \\ ${ }^{2}$ CSIRO Ocean and Atmosphere, Aspendale, VIC, Australia \\ ${ }^{3}$ Finnish Meteorological Institute, Helsinki, Finland
}

Correspondence to: Luke G. Bennetts (luke.bennetts@adelaide.edu.au)

Received: 24 November 2016 - Discussion started: 19 December 2016

Revised: 17 March 2017 - Accepted: 31 March 2017 - Published: 3 May 2017

\begin{abstract}
Impacts of wave-induced breakup of Antarctic sea ice on ice concentration and volume are investigated using a modified version of the CICE sea-ice model, run in standalone mode from 1979-2010. Model outputs show that during summer wave-induced breakup reduces local ice concentration by up to $0.3-0.4$ in a vicinity of the ice edge and total ice volume by up to a factor of $0.1-0.2$.
\end{abstract}

\section{Introduction}

Speculation surrounding the impacts of ocean surface waves on sea ice is building. In the Antarctic, the speculation has been fuelled by findings from Kohout et al. (2014) that trends in ice-edge contraction (from satellite observations) are closely correlated to trends in increasing local significant wave heights (from a numerical model) and, conversely, trends in ice-edge expansion are correlated to trends in decreasing significant wave heights. They attributed these correlations to large-amplitude storm waves propagating into the ice-covered ocean and breaking up the ice cover into relatively small floes, which are more mobile and vulnerable to melting. This relationship can be inferred from descriptions of the way in which waves regulate the morphology of the ice cover in the first 10 to $100 \mathrm{~s}$ of kilometres in from the ice edge, originally made by Squire, Wadhams and co-workers in the 1970s (see, for example, the review by Squire et al., 1995) - a region often referred to as the marginal ice zone, although the term is not adopted in this study due to ambi- guity in its definition. Kohout et al. (2014) suggested that incorporating wave impacts on sea ice into climate models will empower the models to capture sea-ice responses to climate change, for example, the regional variability of trends in Antarctic sea-ice extent (Stammerjohn et al., 2008).

This study constitutes the first quantification of Antarctic sea-ice breakup by waves on ice concentration and volume. It uses a stand-alone version of the CICE sea-ice model, modified to include wave-induced breakup, with wave forcing provided by a Wavewatch III wave-model hindcast in ice-free grid cells close to the ice edge. Wave energy advects into cells containing ice cover, where models of waveenergy attenuation due to ice cover and wave-induced ice breakup are applied, in a similar manner to the operational ice-ocean model wave-ice interaction component developed by Williams et al. (2013a, b).

CICE v4.1 (Hunke and Lipscomb, 2010) is used for the study, in which floe diameters appear in the lateral ice-melt model only, and are set to be $300 \mathrm{~m}$ throughout the ice cover by default. Breakup reduces mean floe diameters typically to $20-100 \mathrm{~m}$ in cells extending $\sim 100 \mathrm{~km}$ in from the ice edge, beyond which the wave energy is no longer strong enough to break the ice. When ocean temperatures are high enough to melt ice, the reduced diameters promote lateral melt, reducing the ice concentration, which, in turn, reduces the ice strength, so that breakup indirectly impacts both ice concentration and volume through dynamic processes. Model outputs show that during the summer wave-induced breakup reduces local ice concentration by up to $0.3-0.4$ and total ice volume by up to a factor of $0.1-0.2$. During the winter, the 
ice concentration recovers, but volume changes persist, becoming dispersed over the inner ice pack.

\section{Model}

CICE uses an ice-thickness-distribution function $g\left(\mathbf{x}_{i j}, t: h\right)$ to describe the sea-ice cover, in which $\mathbf{x}_{i j}$ denotes a grid cell on the ocean surface, indexed $i$ in longitude and $j$ in latitude, $t$ denotes time and $h$ denotes ice thickness, with $g\left(\mathbf{x}_{i j}, t: h\right) \mathrm{d} h$ the fractional area of ice in cell- $i j$ with thickness in the interval $(h, h+\mathrm{d} h)$. The ice-thickness distribution is calculated as a numerical approximation of the icethickness-evolution equation (Thorndike et al., 1975)

$$
\frac{\partial g}{\partial t}=-\nabla \cdot(g \mathbf{u})-\frac{\partial}{\partial h}(f g)+\psi,
$$

using discrete time steps with a nominal global time step $\Delta t=1 \mathrm{~h}$, a horizontal tripolar grid with a nominal resolution of one latitudinal/longitudinal degree, and partitioning of the ice into discrete thickness categories (five categories plus open water are used for this study, as standard). The first term on the right-hand side of Eq. (1) denotes ice advection, where $\mathbf{u}$ is ice velocity, calculated via the elastic-viscous-plastic (EVP) rheology model of Hunke and Dukowicz (1997). The second term denotes thermodynamic thickness redistribution, where $f$ is the rate of melting or freezing. The final term, $\psi$, denotes mechanical redistribution due to ridging.

Waves are introduced into the model using the waveenergy-density spectrum, $S\left(\mathbf{x}_{i j}, t: \omega, \theta\right)$, where $\omega$ and $\theta$ denote angular frequency and wave direction, respectively. This is the standard description of waves in oceanic generalcirculation models. At the beginning of each time step, incident spectra are prescribed in grid cells at a latitude outside the ice cover but as close to the ice cover as possible. For expediency, in each cell at the incident latitude, the wave field is set to be a Bretschneider spectrum, defined by a significant wave height and a peak period, propagating in the mean wave direction. In subsequent cells, directions are calculated as averages of the wave directions entering the respective cells, weighted according to the associated wave energy.

Assuming steady-state conditions over a time step, the spatial distribution of wave energy in the ice-covered ocean is calculated according to a discrete version of the waveenergy-balance equation

$(\cos \theta, \sin \theta) \cdot \nabla S=-\alpha S$.

The attenuation coefficient, $\alpha\left(\mathbf{x}_{i j}, t: \omega\right)$, is set as

$\alpha=\alpha_{0} \equiv c\left(\hat{\alpha}_{2} \omega^{2}+\hat{\alpha}_{4} \omega^{4}\right)$,

where the coefficients

$\hat{\alpha}_{2} \approx 7.68 \times 10^{-5}$ and $\hat{\alpha}_{4} \approx 4.21 \times 10^{-5}$ (units of time ${ }^{2} \times$ distance $^{-1}$ and time ${ }^{4} \times$ distance $^{-1}$, respectively), based on the empirical model from Meylan et al. (2014), scaled according to the areal concentration of sea ice on the ocean surface, $c\left(\mathbf{x}_{i j}, t\right)$.

In each cell, the floe-size distribution is defined by a representative floe diameter $D\left(\mathbf{x}_{i j}\right)$, for consistency with the assumptions underlying the lateral-melt model, described below. At the beginning of a simulation, the diameters are set to the relatively large value $D\left(\mathbf{x}_{i j}\right)=D_{\mathrm{mx}}=300 \mathrm{~m}$, for consistency with the value used throughout the ice cover in existing versions of CICE. For cells in which wave energy is non-negligible, the ice-breakup criterion from Williams et al. (2013a) is applied, with the diameter of the broken floes denoted $D_{\mathrm{bk}}<D_{\mathrm{mx}}$ (no wave impacts on the ice cover are considered beyond breakup). Following wave-induced breakup, the representative floe diameter in cell- $i j$ is calculated as the weighted average

$D\left(\mathbf{x}_{i j}\right)=a_{\mathrm{bk}}\left(\mathbf{x}_{i j}\right) D_{\mathrm{bk}}\left(\mathbf{x}_{i j}\right)+\left(1-a_{\mathrm{bk}}\left(\mathbf{x}_{i j}\right)\right) D_{0}\left(\mathbf{x}_{i j}\right)$,

where $D_{0}$ is the representative diameter in the cell at the beginning of the time step, and $a_{\mathrm{bk}}=L_{\mathrm{bk}} / L_{\mathrm{cl}}$, in which $L_{\mathrm{cl}}$ is the length of the cell in the southwards direction, and $L_{\mathrm{bk}}$ is the distance the wave spectrum propagates southwards through the cell, whilst being attenuated according to Eq. (2), and maintains sufficient energy to cause breakup (Bennetts et al., 2015). For cells at the outermost fringes of the icecovered ocean, where the ice is too thin and compliant to be broken by waves, the floe diameters are assumed to be small and assigned the representative diameter $D=D_{\mathrm{mn}}$.

In cells where breakup occurs, the representative diameter of broken floes, $D_{\mathrm{bk}}$, is calculated by assuming the in-cell floe-size distribution obeys a split power law, as observed by Toyota et al. (2011) (noting that alternative distributions have been postulated for the transition from small to large floes, e.g. Herman, 2010). The probability-density function for the split power law, $p(d)$, where $d$ denotes floe diameter, is defined by

$p(d)=\frac{\mathbb{P}_{0} \beta_{0} \gamma_{0}}{d \gamma_{0}+1} \quad$ if $d \in\left[D_{\mathrm{mn}}, D_{\mathrm{cr}}\right)$,

where $\beta_{0}=\left(D_{\mathrm{mn}}^{-\gamma_{0}}-D_{\mathrm{cr}}^{-\gamma_{0}}\right)^{-1}$,

$p(d)=\frac{\left(1-\mathbb{P}_{0}\right) \beta_{1} \gamma_{1}}{d^{\gamma_{1}+1}}$ if $d \in\left[D_{\mathrm{cr}}, \infty\right)$,

where $\beta_{1}=D_{\mathrm{cr}}^{\gamma_{1}}$,

and $p(d)=0$ if $d<D_{\mathrm{mn}}$ (Williams et al., 2012). Here, $D_{\mathrm{mn}}$ represents a minimum floe diameter, which is chosen to be equal to the small-floe diameter; $D_{\text {cr }}$ is a critical diameter marking the transition from small to large floes (found to be in the range $15-40 \mathrm{~m}$ by Toyota et al., 2011), and $\gamma_{0}=1.15$ and $\gamma_{1}=2.5$ are representative exponents for the small- and large-floe regimes, respectively (Toyota et al., 2011). The quantity $\mathbb{P}_{0} \in[0,1]$ weights the distribution towards small 
floes (large $\mathbb{P}_{0}$ ) or large floes (small $\mathbb{P}_{0}$ ). Its value is set as

$\mathbb{P}_{0}=1-q\left(\frac{D_{\mathrm{pr}}}{D_{\mathrm{cr}}}\right)^{\gamma_{1}}, \quad$ where $\quad D_{\mathrm{pr}}=\lambda / 2$

is the predicted breakup diameter, equal to the distance between successive strain maxima for a regular wave train at the dominant wavelength $\lambda$ for the spectrum $S$, propagating through an infinitely long, uniform floe (Williams et al., 2013a; Bennetts et al., 2015), so that a chosen proportion $q$ of floe diameters are greater than $D_{\mathrm{pr}}$. In the uncommon event that $D_{\text {pr }}<D_{\text {cr }}$ then $\mathbb{P}_{0}=0$, noting that $D_{\text {cr }}$ approximates the theoretical diameter below which flexural breakup cannot occur (Toyota et al., 2011). The broken-floe diameter $D_{\mathrm{bk}}$ is the mean diameter

$$
\begin{aligned}
D_{\mathrm{bk}} & =\int_{D_{\mathrm{mn}}}^{\infty} p(d) d \mathrm{~d} d=\frac{\mathbb{P}_{0} \gamma_{0} \beta_{0}\left(D_{\mathrm{mn}}^{1-\gamma_{0}}-D_{\mathrm{cr}}^{1-\gamma_{0}}\right)}{\gamma_{0}-1} \\
+ & \frac{\left(1-\mathbb{P}_{0}\right) \gamma_{1} \beta_{1} D_{\mathrm{cr}}^{1-\gamma_{1}}}{\gamma_{1}-1} .
\end{aligned}
$$

The breakup model is applied at the beginning of each CICE time step, allowing the reduced floe diameters to affect other CICE-model components. The reduced diameters directly affect the fraction of ice that melts laterally, $r_{\text {lat }}$, via the discrete version of the model from Steele (1992):

$r_{\text {lat }}=\frac{\pi \Delta t w_{\text {lat }}}{\mu D}$,

which assumes floes in a given cell are identical. Here $\mu=$ 0.66 is a geometric parameter and $w_{\text {lat }}=1.6 \Delta T^{2} \times 10^{-6}$ (units of distance $\times$ time $^{-1}$ ) is the rate of lateral melt, in which $\Delta T$ is the temperature difference of the sea surface above that of the bottom of the ice (set to zero if the difference is negative). The diameters are updated at the end of the thermodynamic routine to account for lateral melt.

During the summer months, when the ice is weaker and towards its minimum extent, waves cause breakup close to the coastline. The existing thermodynamic models in CICE do not increase the diameters of these broken floes fast enough through the winter to create a realistic seasonal cycle for the floe-diameter distribution. Therefore, an ad-hoc floe-bonding scheme is applied, in which the floe diameter in a given cell is doubled if the freezing potential in that cell is positive, up to the maximum diameter $D_{\mathrm{mx}}$.

The representative diameter, $D$, is transported by (i) setting the floe diameter to be identical for each of the different thickness categories, and transporting the floe diameter as an area tracer for the different thickness categories; and (ii) setting the new representative diameters to be the diameters of the thinnest ice category (cat. 1). Step (ii) is a non-physical simplifying assumption; tests indicate that this assumption does not affect the concentration changes due to breakup presented in Sect. 3.

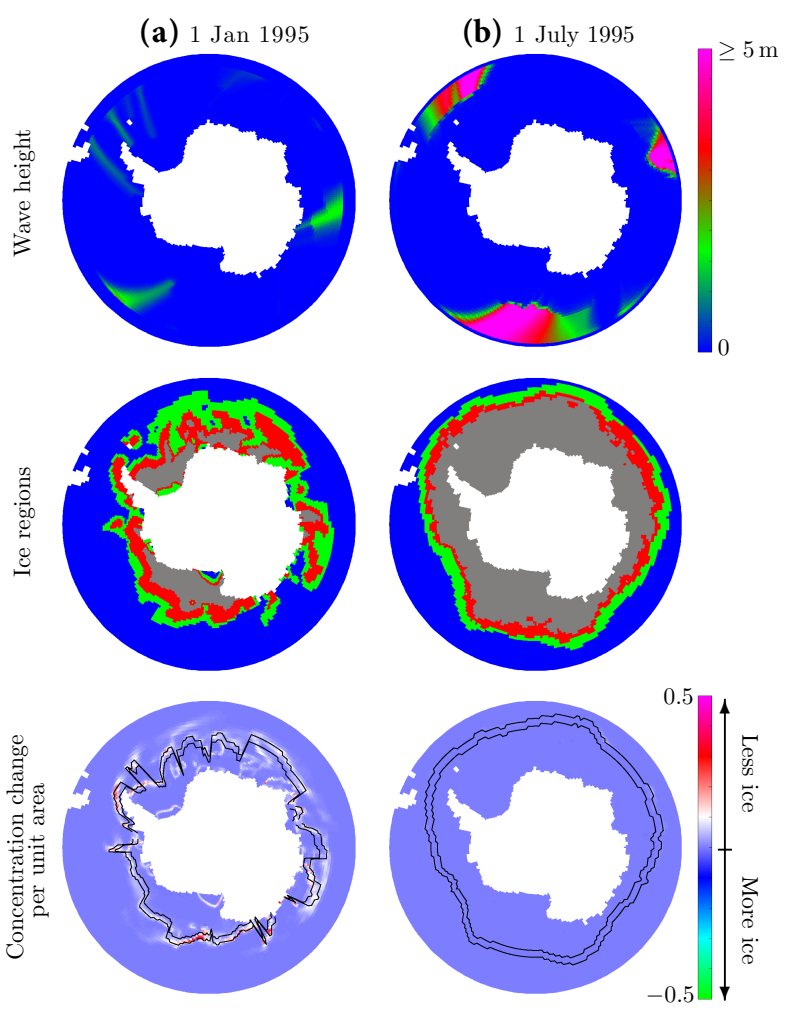

Figure 1. Example model outputs using $D_{\mathrm{mn}}=5 \mathrm{~m}, D_{\mathrm{cr}}=30 \mathrm{~m}$ and $q=0.05$. The left-hand column (a) is representative of results in austral summer and the right-hand column (b) of winter. The top row shows the significant wave heights. The middle row shows the ice regions: small floes (green), wave-broken floes (red), unbroken floes (grey) and no ice/open water (blue). The bottom row shows the change in concentration between the simulations without and with breakup.

\section{Results}

The model was run from 1979 to 2010 using input wave data generated by a Wavewatch III model hindcast (Durrant et al., 2013) and atmospheric and oceanic data from the U. S. National Centers for Environmental Prediction's Climate Forecast System Reanalysis (NCEP's CFSR, Saha et al., 2010). The minimum and critical floe diameters were set as $D_{\mathrm{mn}}=$ $5 \mathrm{~m}$ and $D_{\mathrm{cr}}=30 \mathrm{~m}$, and, following breakup, the proportion $q=0.05$ of floe diameters was set to be greater than the predicted breakup diameter $D_{\mathrm{pr}}$.

Figure 1 shows example model outputs for two dates during 1995 (i.e. a year half-way through the simulation), representative of results in summer (1 January, left-hand panels) and winter (1 July, right). The panels in the top row show significant wave heights, with the sharp outer boundaries of non-zero wave heights indicating the latitudes at which data is extracted from the wave model. This boundary is farther north in the winter because the ice extent is greater than in the summer. The regions of rapid wave-height decrease with 
respect to southward distance indicate attenuation of wave energy due to ice cover. In the summer, packets of wave energy are able to propagate almost to the coastline, particularly around the Antarctic peninsula, due to reduced ice cover in that locality.

The middle row shows the extent of ice coverage, with the ice divided into regions according to floe size. Regions of small diameter floes (green) are identified as those cells for which $D \leq D_{\mathrm{mn}}=5 \mathrm{~m}$, wave-broken floes (red) are the floesize interval $D_{\mathrm{mn}}<D \leq 250 \mathrm{~m}$ and unbroken floes (grey) are $D>250 \mathrm{~m}$. The bottom row shows the impact of the small and broken floes on ice concentration, in terms of the difference in concentration between the simulation without breakup $(D=300 \mathrm{~m})$ and the simulation with breakup, with positive values indicating decreases in concentration due to breakup.

The Southern Ocean experiences the strongest waves during winter, as indicated in the top row. However, the areas covered by regions of broken ice are comparable between the two seasons (approximately $10 \%$ smaller in the summer for the dates shown in the middle row), as the lower summer ice concentration allows waves to penetrate deeper into the ice-covered ocean, relative to their incident energy. The ice is structured into approximately uniform bands in the winter, whereas in the summer coastal effects complicate the structure.

In the summer, the broken ice decreases the ice concentration in a vicinity of the ice edge, with reductions of $\sim 0.1$ common but with numerous pockets of 0.3-0.4 reductions apparent. The region most impacted by breakup is estimated by the region bounded by the two black lines, where the outer black line denotes the first cell (with respect to each longitude) at which the ice concentration exceeds 0.1 , and the inner black line represents three cells farther in (or land if that begins before the third cell). During the winter, the concentration change is too small to be visible on the scale shown (order 0.01), as the temperatures are too low to melt the broken floes.

Figure 2 shows mean monthly ice concentrations at the ice edge (the region bounded by the black lines in the bottom row of Fig. 1) for each simulation year. Results are again shown for January and July, as representations of summer and winter conditions, respectively. Data were generated by simulations without breakup $(x)$ and with breakup (red $\bullet$ ). For the summer conditions, additional data indicate sensitivities of concentration changes to (i) the floe-size parameters, with data given for simulations in which $D_{\mathrm{mn}}, D_{\mathrm{cr}}$ and $q$ are decreased to $D_{\mathrm{mn}}=2.5 \mathrm{~m}, D_{\mathrm{cr}}=20 \mathrm{~m}$ and $q=$ 0.025 (green $\mathbf{\nabla}$ ) and increased to $D_{\mathrm{mn}}=10 \mathrm{~m}, D_{\mathrm{cr}}=40 \mathrm{~m}$ and $q=0.1$ (green $\mathbf{\Delta}$ ); and (ii) increasing or decreasing the wave-attenuation coefficient, $\alpha$, by an order of magnitude ( $\alpha=10 \alpha_{0}$, grey $\mathbf{\Delta}$, and $\alpha=\alpha_{0} / 10$, grey $\mathbf{\nabla}$, respectively). The ranges of floe sizes and attenuation rates are within the limits of present uncertainty. (a) January

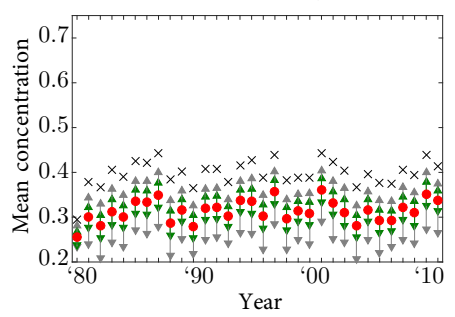

(b) July

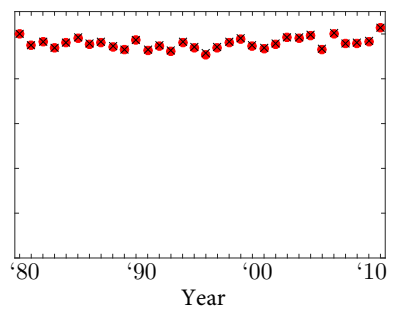

Figure 2. Mean monthly ice concentrations at the ice edge (the region bounded by the black lines in the bottom row of Fig. 1), for January (a) and July (b). Results are for the simulation without breakup $(x)$ and with breakup for the parameters considered in Fig. $1\left(D_{\mathrm{mn}}=5 \mathrm{~m}, D_{\mathrm{cr}}=30 \mathrm{~m}\right.$, and $q=0.05$, red $\left.\bullet\right)$; smaller floes $D_{\mathrm{mn}}=2.5 \mathrm{~m}, D_{\mathrm{cr}}=20 \mathrm{~m}$ and $q=0.025$ (green $\boldsymbol{\nabla}$ ); larger floes $D_{\mathrm{mn}}=10 \mathrm{~m}, D_{\mathrm{cr}}=40 \mathrm{~m}$ and $q=0.1$ (green $\boldsymbol{\Lambda}$ ); a decreased attenuation rate $\alpha=\alpha_{0} / 10$ (grey $\boldsymbol{\nabla}$ ); and an increased attenuation rate $\alpha=10 \alpha_{0}$ (grey $\mathbf{\Delta}$ ).

As indicated by the bottom-right panel of Fig. 1, the righthand panel of Fig. 2 shows that breakup has negligible impact on ice concentration during winter. During the summer, breakup reduces the concentration, with the mean decrease being $\sim 0.08$ for the parameters used in Fig. 1 (neglecting the first, spin-up year of the simulation). Reducing the floe-size parameters increases the impact of breakup (as smaller floes melt more rapidly than larger ones), and increasing them reduces the impact, with the mean reductions compared to the simulation without breakup being $\sim 0.11$ and 0.06 , respectively. Similarly, reducing the attenuation rate increases the impact (as the waves maintain their strength for greater distances into the ice-covered ocean), and increasing the attenuation rate has the opposite effect - the mean reductions are $\sim 0.15$ and 0.04 , respectively.

The top panels of Fig. 3 show changes in ice volume per unit area due to breakup, for the two dates used in Fig. 1, i.e. results representative of summer (1 January 1995, lefthand panel) and winter (1 July 1995, right). During the summer, breakup decreases the ice volume, particularly at the ice edge, where losses of $\sim 0.5 \mathrm{~m}$ per unit area are common. The pattern of the decreases is strongly correlated with the concentration decreases shown in the bottom-left panel of Fig. 1. During the winter, regions of volume loss $0.1-0.3 \mathrm{~m}$ per unit area are visible in the interior of the ice cover (the unbroken ice region). This contrasts with the negligible concentration losses on the same date shown in the bottom-right panel of Fig. 1. The volume losses result from summer thickness reductions forced by dynamic processes being restored at a slower rate than concentration. Ice advection disperses the losses over large regions.

The bottom-left panel of Fig. 3 shows volume decreases due to breakup as proportions of the total ice cover without breakup, over a typical 6-year interval. The ice volumes 
(a) 1 Jan 1995

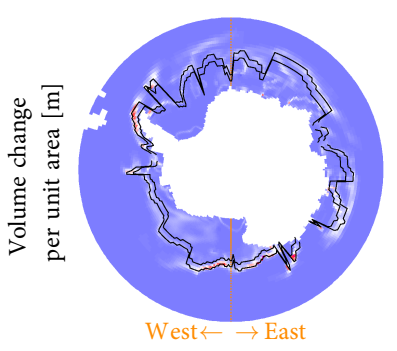

(c) Proportional volume decrease

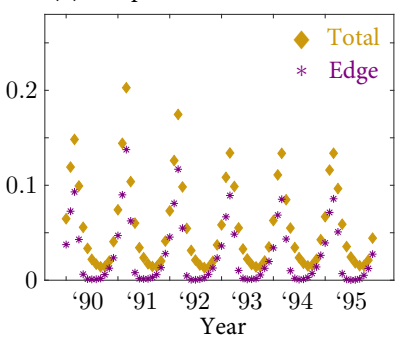

(b) 1 July 1995

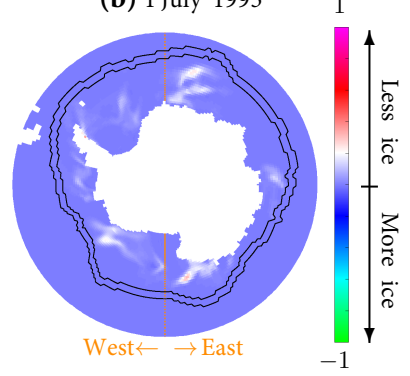

Volume decrease per degree latitude $\left[\mathrm{km}^{3} \mathrm{deg}^{-1}\right]$

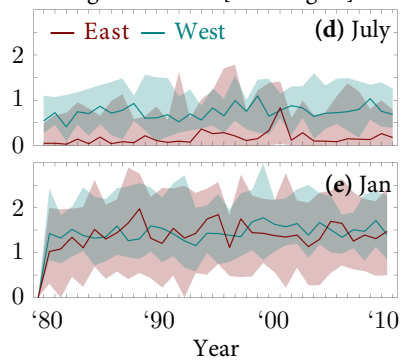

Figure 3. (a, b) Snapshots of ice volume changes per unit area between simulations without and with breakup $\left(D_{0}=5 \mathrm{~m}, D_{\mathrm{cr}}=\right.$ $30 \mathrm{~m}$ and $q=0.05$ ). (c) Proportional volume decreases on first day of month over total ice cover (yellow $\$$ ) and at ice edge (purple $*$ ), for 1990-1995. (d, e) Median decrease in ice volume per degree latitude for the eastern sector (red - ) and the western sector (green -), on 1 January (e) and 1 July (d) for all simulation years. Shaded regions show corresponding 25 th to 75 th percentile ranges.

are sums over the total ice cover (for cells with concentrations greater than 0.1 , yellow $)$ and cells at the ice edge (the region between the black lines, purple $*$ ). Seasonal cycles are evident, with, for example, peaks in both proportions occurring in March; the peaks for the full cover are between 0.13 and 0.20 , and the peaks at the ice edge are between 0.09 and 0.14. During June and July, losses at the ice edge due to wave-induced breakup typically contribute less than $5 \%$ of the total volume losses, whereas during November-March a large proportion (54-68\%) of the overall losses occur at the ice edge, as indicated in the top-left panel of Fig. 3.

The bottom-right panels of Fig. 3 show decreases in total ice volume per degree latitude on 1 January (bottom panel) and 1 July (top), over the full 32 years of the simulations, in terms of the median values, and the spread in terms of the 25th and 75th percentiles. Data are split into losses in the eastern (red -) and western (green -) sectors of Antarctica (as shown in the top panels of Fig. 3). During the summer, when the increased lateral melt of the reduced floe diameters impacts ice concentration, volume losses in the two sectors are similar. However, only the western sector carries the bulk of its volume loss into winter, as a significant proportion of East Antarctic sea ice affected by breakup during early-

mid summer melts during February, so that the winter ice is largely composed of new ice.

\section{Discussion}

The findings of this pilot study indicate that increased lateral sea-ice melt over the first $\sim 100 \mathrm{~km}$ in from the ice edge, due to small wave-broken floes, and the follow-on effects on ice dynamics, impact ice concentration and volume in a vicinity of the edge during winter and ice volume in the interior pack throughout the year. The coupled iceocean-atmosphere model by Horvat et al. (2016), which includes interactions between floe diameters, ocean circulation and ice melt, indicates that lateral melt remains important for sea-ice evolution for floe diameters orders of magnitude larger than the $\mathrm{O}(30 \mathrm{~m})$ limit given by the model from Steele (1992), as used in CICE. Presumably, therefore, integrating diameter-circulation-melt interactions into the modified version of CICE would strengthen the impacts of breakup. Moreover, integrating the granular floe-size-dependent rheology of Feltham (2005) would provide a direct impact of breakup on ice dynamics. Applying the modified CICE model in a fully coupled setting will unlock feedbacks triggered by the breakup - for example, the reduced concentration due to increased lateral melt releasing more oceanic heat to the atmosphere, thus increasing upwelling of ocean heat through convection and hence promoting further ice melt - permitting studies into influences on long-term trends in ice concentration, volume and also extent. If further research finds the impacts of floe-size-dependent processes to be significant, future large-scale sea-ice models may be developed along the lines of the theories for coupled ice-thickness and floe-size evolution outlined by Zhang et al. (2015) and Horvat and Tziperman (2015).

Code availability. The Australian Antarctic Data Centre hosts the code used for this study at doi:10.4225/15/57D0EA42ED985 (Bennetts, 2016).

Data availability. For input wave data see Durrant et al. (2013), and for atmospheric and oceanic data see Saha et al. (2010).

Competing interests. The authors declare that they have no conflict of interest.

Acknowledgements. The authors thank Mark Hemer for providing advice on the wave data used and an internal CSIRO review of the original version of the paper and the two anonymous referees and Christopher Horvat for their valuable comments. The Australian Research Council (DE130101571) and the Australian Antarctic Science Program (Project 4123) funded this investigation. The 
Academy of Finland supports PU (Contract 264358).

Edited by: D. Notz

Reviewed by: two anonymous referees

\section{References}

Bennetts, L.: Wave-ice breakup model for inclusion in CICE Australian Antarctic Data Centre - CAASM Metadata (https: //data.aad.gov.au/metadata/records/AAS_4123_CICE-Model), 2016, updated 2016.

Bennetts, L. G., O'Farrell, S., Uotila, P., and Squire, V. A.: An idealised wave-ice interaction model without subgrid spatial or temporal discretisations, Ann. Glaciol., 56, 258-262, 2015.

Durrant, T., Hemer, M., Trenham, C., and Greenslade, D.: CAWCR Wave Hindcast 1979-2010. v7, Tech. rep., CSIRO. Data Collection, doi:10.4225/08/523168703DCC5, 2013.

Feltham, D. L.: Granular flow in the marginal ice zone, Phil. Trans. R. Soc. Lond. A, 363, 1677-1700, doi:10.1098/rsta.2005.1601, 2005.

Herman, A.: Sea-ice floe-size distribution in the context of spontaneous scaling emergence in stochastic systems, Phys. Rev. E, 81, 066123, doi:10.1103/PhysRevE.81.066123, 2010.

Horvat, C. and Tziperman, E.: A prognostic model of the sea-ice floe size and thickness distribution, The Cryosphere, 9, 21192134, doi:10.5194/tc-9-2119-2015, 2015.

Horvat, C., Tziperman, E., and Campin, J.-M.: Interaction of sea ice floe size, ocean eddies, and sea ice melting, Geophys. Res. Lett., 43, 8083-8090, doi:10.1002/2016GL069742, 2016.

Hunke, E. C. and Dukowicz, J. K.: An elastic-viscous-plastic model for sea ice dynamics, J. Phys. Oceangr., 27, 1849-1867, 1997.

Hunke, E. C. and Lipscomb, W. H.: CICE: the Los Alamos Sea Ice Model Documentation and Software User's Manual Version 4.1 (LA-CC-06-012), Tech. rep., T-3 Fluid Dynamics Group, Los Alamos National Laboratory, 2010.

Kohout, A. L., Williams, M. J. M., Dean, S. M., and Meylan, M. H.: Storm-induced sea-ice breakup and the implications for ice extent., Nature, 509, 604-607, doi:10.1038/nature13262, 2014.

Meylan, M. H., Bennetts, L. G., and Kohout, A. L.: In-situ measurements and analysis of ocean waves in the Antarctic marginal ice zone, Geophys. Res. Lett., 41, 5046-5051, 2014.
Saha, S., Moorthi, S., Pan, H.-L., Wu, X., Wang, J., Nadiga, S., Tripp, P., Kistler, R., Woollen, J., Behringer, D., Liu, H., Stokes, D., Grumbine, R., Gayno, G., Wang, J., Hou, Y.-T., Chuang, H.Y., Juang, H.-M. H., Sela, J., Iredell, M., Treadon, R., Kleist, D., Van Delst, P., Keyser, D., Derber, J., Ek, M., Meng, J., Wei, H., Yang, R., Lord, S., van den Dool, H., Kumar, A., Wang, W., Long, C., Chelliah, M., Xue, Y., Huang, B., Schemm, J.-K., Ebisuzaki, W., Lin, R., Xie, P., Chen, M., Zhou, S., Higgins, W., Zou, C.-Z., Liu, Q., Chen, Y., Han, Y., Cucurull, L., Reynolds, R. W., Rutledge, G., and Goldberg, M.: NCEP Climate Forecast System Reanalysis (CFSR) 6-hourly Products, January 1979 to December 2010, doi:10.5065/D69K487J, 2010.

Squire, V. A., Dugan, J. P., Wadhams, P., Rotter, P. J., and Liu, A. K.: Of ocean waves and sea ice, Annu. Rev. Fluid Mech., 27, 115$168,1995$.

Stammerjohn, S., Martinson, D. G., Smith, R. C., Yuan, X., and Rind, D.: Trends in Antarctic sea ice retreat and advance and their relation to El Nino-Southern Oscillation and southern annular mode variability, J. Geophys. Res.-Oceans, 113, C3, 2008.

Steele, M.: Sea ice melting and floe geometry in a simple ice-ocean model, J. Geophys. Res., 94, 17729-17738, 1992.

Thorndike, A. S., Rothrock, D. A., Maykut, G. A., and Colony, R.: The thickness distribution of sea ice, J. Geophys. Res., 80, 4501, doi:10.1029/JC080i033p04501, 1975.

Toyota, T., Haas, C., and Tamura, T.: Size distribution and shape properties of relatively small sea-ice floes in the Antarctic marginal ice zone in late winter, Deep-Sea Res. Pt. II, 58, 11821193, doi:10.1016/j.dsr2.2010.10.034, 2011.

Williams, T. D., Bennetts, L. G., Squire, V. A., Dumont, D., and Bertino, L.: Towards the inclusion of wave-ice interactions in large-scale models for the Marginal Ice Zone, ArXiV, arXiv:1203.2981v1, 2012.

Williams, T. D., Bennetts, L. G., Dumont, D., Squire, V. A., and Bertino, L.: Wave-ice interactions in the marginal ice zone. Part 1: Theoretical foundations, Ocean Model., 71, 81-91, $2013 \mathrm{a}$.

Williams, T. D., Bennetts, L. G., Dumont, D., Squire, V. A., and Bertino, L.: Wave-ice interactions in the marginal ice zone. Part 2: Numerical implementation and sensitivity studies along 1D transects of the ocean surface, Ocean Model., 71, 92-101, doi:10.1016/j.ocemod.2013.05.011, 2013b.

Zhang, J., Schweiger, A., Steele, M., and Stern, H.: Sea ice floe size distribution in the marginal ice zone: Theory and numerical experiments, J. Geophys. Res., 120, 3484-3498, 2015. 